\title{
CULTURA MATERIAL DE LA ESCUELA E HISTORIA INTELECTUAL
}

\author{
SCHOOL MATERIAL CULTURE AND INTELLECTUAL HISTORY
}

\section{CULTURA MATERIAL DA ESCOLA E HISTÓRIA INTELECTUAL}

\begin{abstract}
Agustín Escolano Benito ${ }^{1}$
RESUMEN

Este ensayo propone algunas reflexiones y sugerencias en orden a plantear la necesidad de repensar la cultura material de la escuela, un campo que se ha ido configurando en los últimos años como corriente historiográfica innovadora en la historia intelectual de la educación. Material e intelectual no se contraponen, como pudiera a primera vista sospecharse, toda vez que la consideración de las materialidades como objetos y como contenidos por parte de la historiografía contemporánea, y no solo como fuente, obedece a una operación de la historia cultural que se ha de llevar a cabo desde presupuestos intelectuales. De no ser así, la operación histórica se reduciría a ser una mera construcción etnográfica, y por consiguiente no trascendería la orientación positivista e instrumental del análisis. La visión intelectual de lo material cambia la episteme e introduce una nueva crítica en la cultura material.
\end{abstract}

PALABRAS-CLAVE: Cultura material de la escuela, Historia de la experiencia, Historia intelectual, Materiales con cultura, El tercer maestro, Patrimonio histórico-educativo.

\section{ABSTRACT}

This essay proposes some reflections and suggestions in order to raise the need to rethink the material culture of the school, a field that has been shaping up in recent years as an innovative historiographic trend in the intellectual history of education. Material and intellectual are not opposed, as might be suspected at first sight, since the consideration of materialities as objects and as contents by contemporary historiography, and not only as a source, is due to an operation of cultural history that it has to be carried out from intellectual presumptions. Otherwise, the historical operation would be reduced to a mere ethnographic construction, and therefore it would not transcend the positivist and instrumental orientation of the analysis. The intellectual vision of the material changes the episteme and introduces a new criticism in the material culture

KEYWORDS: Material culture of the school. Experience history. Intellectual history. Materials with culture. The third teacher. Historical-educational heritage.

\footnotetext{
${ }^{1}$ Licenciado en Filosofía y Letras, sección Pedagogía, Universidad Complutense de Madrid. Doctor en Educación, Universidad de Madrid. Profesor jubilado del Departamento Teoría e Historia de la Educación en la Facultad de Educación y Trabajo Social, Universidad de Valladolid. Director del Centro Internacional de Cultura Escolar-CEINCE. E-mail: ceince@ceince.eu
}

Submetido em: 22/06/2020 - Aceito em: 21/09/2020 


\section{RESUMO}

Este ensaio propõe algumas reflexões e sugestões para levantar a necessidade de repensar a cultura material da escola, um campo que vem se configurando nos últimos anos como uma tendência historiográfica inovadora na história intelectual da educação. O material e o intelectual não se opõem, como se pode suspeitar à primeira vista, uma vez que a consideração das materialidades como objetos e conteúdos pela historiografia contemporânea, e não apenas como fonte, obedeça a uma operação da história cultural que deve ser realizada a partir de pressupostos intelectuais. Caso contrário, a operação histórica seria reduzida a ser uma mera construção etnográfica e, portanto, não transcenderia a orientação positivista e instrumental da análise. A visão intelectual do material muda a episteme e introduz uma nova crítica na cultura material.

PALAVRAS-CHAVE: Cultura material da escola. História da experiência. História intelectual. Materiais com cultura. O terceiro professor. Patrimônio histórico-educativo.

\section{LA EXPERIENCIA: HISTORIA MATERIAL/ INTELECTUAL}

La historia material es un vector esencial de toda historia de la experiencia. También lo es de las ciencias humanas que se ocupan de explicar e interpretar algún ámbito del mundo de la vida. Hay experiencias que no requieren materiales específicos, pero siempre se escenifican en espacios que son materiales y mediante acciones que remiten a elementos físicos de la situación. El retorno a la empeiría que se ha operado en general en la historiografía y en la mayor parte de las ciencias sociales supone en cierto modo una especie de giro, de orientación aristotélica, que trata de corregir las desviaciones racionalistas e ideológicas que han dominado en los saberes acerca de la educación, incluida la historia. Busca asimismo tratar de entender las relaciones que los sujetos entablan con las cosas en los contextos en los que se llevan a cabo las acciones de las prácticas de la formación, es decir, en los entornos de las mismas instituciones de educación formal.

Las cosas, en cuanto materialidades que son, pertenecen incuestionablemente al mundo de la experiencia. En ella se fraguaron y a ella se implementaron. Es por tanto el mundo de la experiencia el que funda la episteme de los usos culturales de la realidad, y el que remite a los métodos, las fuentes y los contenidos de la historia material de la escuela. $Y$ ello es así porque lo material y lo intelectual - conviene advertirlo- no se contraponen, como pudiera a primera vista sospecharse, toda vez que la consideración de las materialidades como objeto y como fundamentación de los estudios acerca del pasado, y no solo como recurso técnico o instrumental, obedece a una operación de la historia cultural que se ha de llevar a cabo siempre y de forma inequívoca desde presupuestos intelectuales. De no ser así, la operación histórica, de la que hablaba Michel de Certeau, que partiera de la experiencia no reflexionada y de las simples materialidades, se reduciría a una mera y epidérmica construcción etnográfica, que no trascendería por consiguiente la simple orientación positivista del análisis. 
La cuestión que aquí se plantea al asociar lo material con lo intelectual se origina en algunos debates suscitados en la propia comunidad académica de historiadores de la educación que viene sugiriendo desde hace algún tiempo la necesidad de interpretar con más complejidad y rigor crítico el alcance y sentido que puede tener este tipo de cultura escolar que se define a sí misma desde la categoría historiográfica de lo matérico. Pero, además, desde otra perspectiva, la que se afirma conforme a los supuestos de la construcción social del conocimiento, se ha de considerar que no solo es la academia sino toda la sociedad la que apoya la operación de reconstruir y repensar el patrimonio de la educación como objeto histórico, el material y el inmaterial, al considerar que este acervo es un elemento cultural esencial, de fuertes valencias gnoseológicas y formativas, que ha de ser asumido en una sociedad ilustrada y democrática como un bien público y común y como una fuente de saber acerca de los procesos de alcance antropológico que han orientado la construcción pedagógica de la formación humana. Este reconocimiento es, asimismo, además de un hecho sociocultural, una actitud que revela la naturaleza intelectual de la operación histórica.

Por todo lo anterior, justamente los contenidos de la cultura material de la escuela han entrado ya a formar parte, a través principalmente de los programas museográficos y de las investigaciones acerca de la memoria histórica, de los espacios públicos que las comunidades ofrecen para su conservación, estudio y disfrute. También se ha integrado este tipo de cultura en el plano académico, en los programas de formación de los profesionales de la enseñanza, los profesores, y en el plano comunitario, esto es, en la educación histórica no formal de toda la ciudadanía. Esta, la ciudadanía, que se ha visto sometida durante tiempos largos a las disciplinas, los procesos y los métodos de la escolarización, tiene de esta manera la posibilidad de reflexionar sobre su propio desarrollo formativo a partir de la observación y el estudio de los restos materiales en los que quedó registrada la cultura de la escuela y que ahora ofrecen los centros de memoria.

Este ensayo quiere llamar la atención al tiempo, en primer lugar, sobre una cuestión que no ha sido a nuestro entender suficientemente ponderada, a saber: que el interés por lo material como hecho de cultura no es tan nuevo como pudiera parecer, aunque hoy se pueda percibir como una preocupación mejor motivada y más asentada, y sin duda, mejor documentada por los registros de mayor visibilidad que se construyen. Nuestro tiempo, apoyado en los potentes visores que proporcionan las nuevas tecnologías, y en la lógica de la llamada cultura simulacro - atenta a menudo más a las representaciones que a las voluntades o intenciones-, se ha hecho sin duda más performativo, pero a la vez ha trivializado y simplificado algunos análisis y tratamientos acerca de los objetos y las imágenes que se manejan. No obstante lo anterior, no conviene olvidar que el ya clásico materialismo histórico y las llamadas filosofías posestructurales destacaron el poder de lo matérico como fuerza transformadora de la realidad, así como el interés hermenéutico de la dimensión semántica depositada, como cultura implícita, en las cosas mismas. En las últimas décadas, la sociología

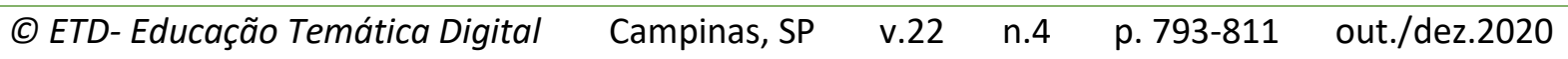


de la cultura también ha revalorizado el ámbito de lo material, tratando de no caer en ejercicios neopositivistas o en el espontaneísmo etnográfico. No es nuevo pues el reclamo de lo material como testimonio y prueba de una cultura y como estímulo para la reflexión intelectual acerca de ella.

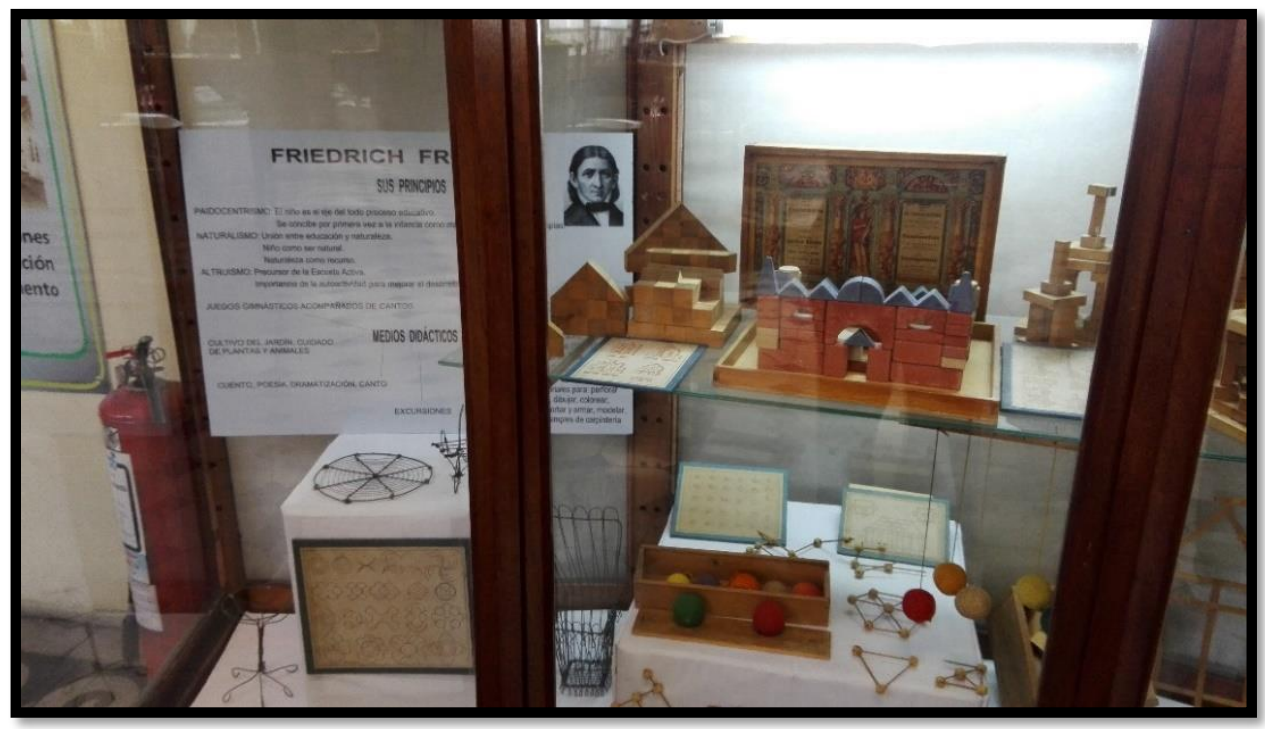

Figura 1 - Froebel Montevideo. Museo Pedagógico José Pedro Varela Uruguay - Fonte: Agustín Escolano

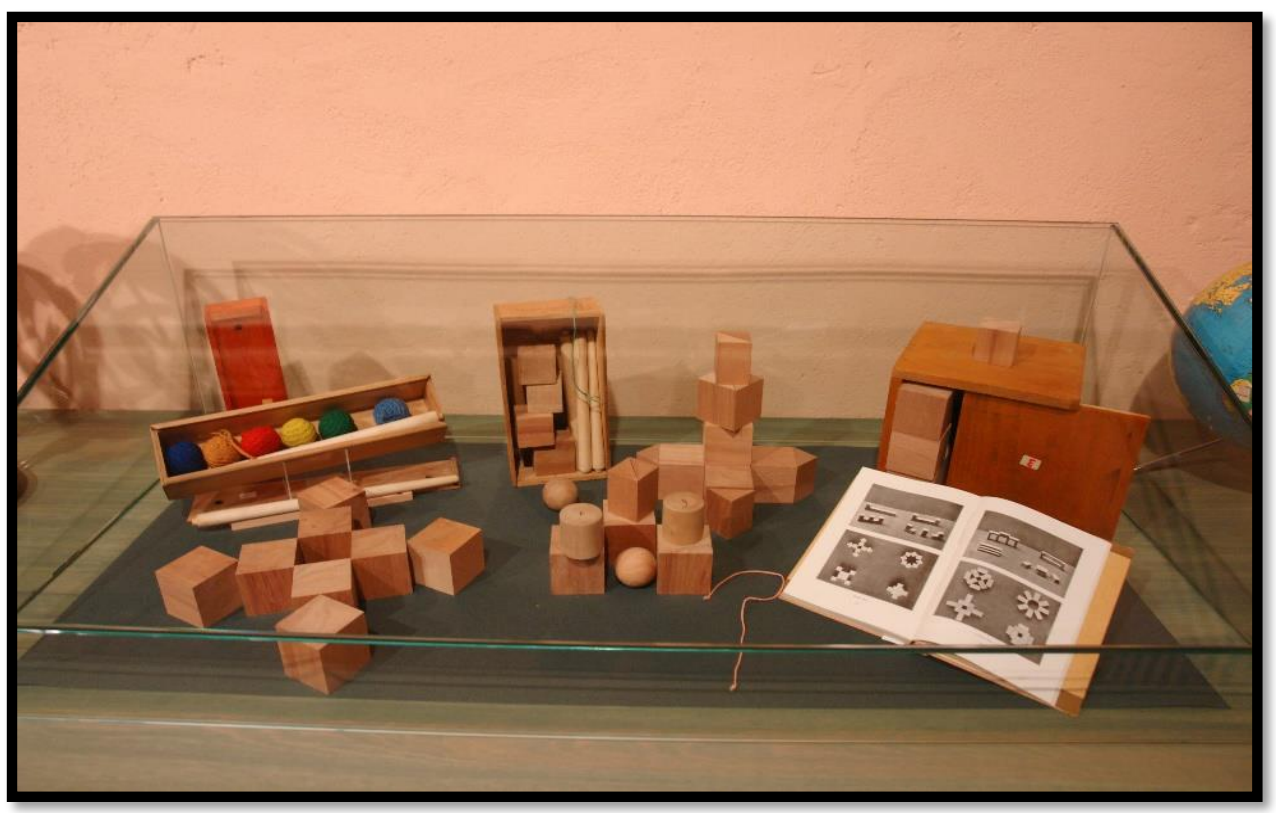

Figura 2 - Froebel - CEINCE - Exposición estable del Centro Internacional de la Cultura Escolar - CEINCE - España - Fonte: Agustín Escolano. 


\subsection{La inteligencia de las cosas}

Algunos materiales escolares tienen una semántica bien acreditada. No solo se concibieron y usaron para instrumentar acciones de enseñanza y aprendizaje sino que comportaban una determinada e intuible "inteligencia". En otros objetos las significaciones pueden ser menos visibles, pero en estos que aquí se presentan son manifiestos los atributos culturales que acompañan a su mera fisicalidad, lo que requiere un análisis "intelectual" de los materiales.

Los prototipos del sistema Froebel, objetos definidos como "dones", se concibieron por su creador como una representación "intelectual" del universo en sus formas esenciales, al igual que los sólidos del platonismo. Todo lo observable en la naturaleza y en el arte podía ser reducido a unas pocas formas básicas y a sus combinaciones. La esfera transmitía la idea de movimiento; el cubo, la de estabilidad; y el cilindro, la del equilibrio dinámico. Mediante la observación y manipulación lúdica de estos "dones", los niños internalizaban estructuras y dinamismos inscritos en las materialidades, organizando así la estructura de su mente topológica y los símbolos de la realidad y de la cultura (LAHOZ, 1991).

La semántica que comportan estos objetos acredita el valor cultural de unas materialidades ideadas por su autor a mitad del siglo XIX, que aún hoy siguen formando parte de las pedagogías innovadoras. Esta larga vigencia sugiere un valor algorítmico o "inteligente" adherido a unas microestructuras materiales que pudieron influir incluso en modelos arquitectónicos como los de Wright y Le Corbusier, entre otros. Al examinar estos objetos, los analistas se plantean incluso el mito de origen, del que habló Baudelaire, de estos "dones" que nacieron para durar.

La vitrina mayor de la ilustración corresponde a los materiales del sistema Froebel que obran en el Museo Pedagógico de Montevideo, creado en la capital uruguaya en 1889. La vitrina menor, de la exposición "Mi Querida Escuela" del CEINCE, muestra algunos "dones" froebelianos junto al libro guía de las prácticas que han de desarrollar con ellos los maestros y los niños. 


\section{(C) (1) (9)}

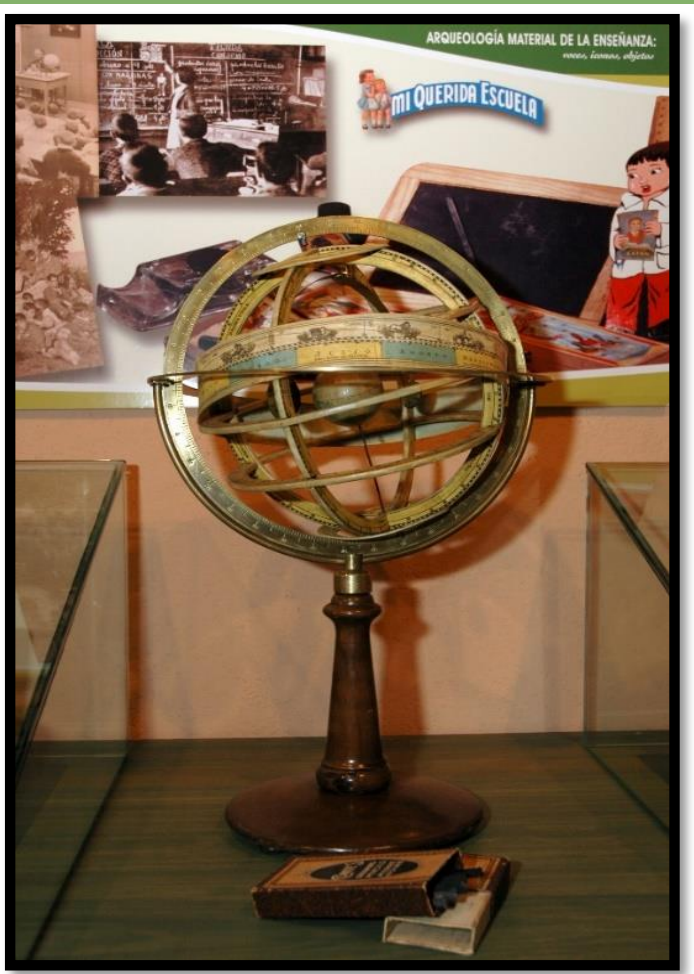

Figura 3 - Esfera armilar

Exposición estable del Centro Internacional de la Cultura Escolar - CEINCE - España

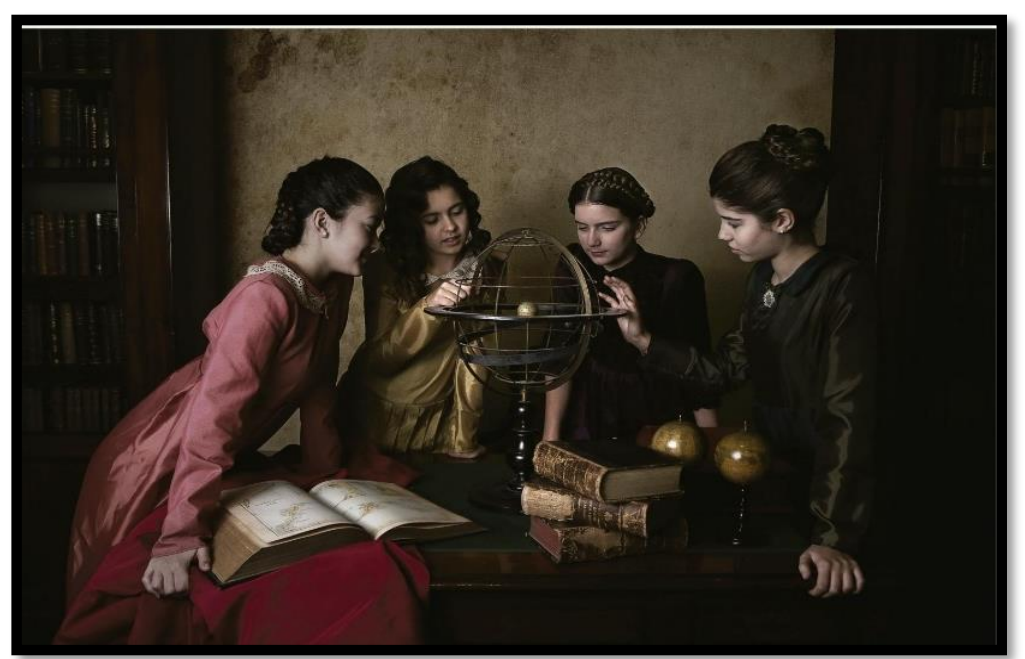

Figura 4 - Telurio MV

Museo Pedagógico José Pedro Varela - Uruguay Fonte: Agustín Escolano 


\subsection{Esfera Armilar y Telurio}

Otro objeto escolar cargado de "inteligencia" es la conocida esfera armilar, una mediación material incluida en muchos de los catálogos de material de enseñanza. Este artefacto sintetizaba los elementos configuradores y las órbitas dinámicas que formaban parte del sistema de representación del mundo, imagen a escala humana de la visión del universo que transmitió la educación formal en todas las escuelas del mundo.

Este objeto, junto a otros como el telurio y los globos terráqueos, proporcionaron una idea del mundo que no ofrecían los atlas y los mapas, que solo mostraban una representación plana de las realidades geográficas y cosmológicas. Su globalidad y su dinamismo mostraron a los niños y maestros muchas posibilidades didácticas y lúdicas del artefacto, que en su origen pudo ser una tecnología vernácula ideada en la misma práctica escolar. La imagen que acompaña a esta anotación es en realidad un montaje en el que varias adolescentes observan sobre un telurio la explicación de un eclipse. Procede del Museo Pedagógico José Pedro Varela, de Montevideo, Uruguay.

Además, en la observación y manejo de estos medios didácticos, los estudiantes siempre intuyeron la magia inherente al cosmos, más allá de la funcionalidad que las esferas podían tener en orden a la localización de lugares y el cálculo de distancias y tiempos. Los viajes imaginarios infantiles sirvieron para construir relatos y otras formas de expresión literaria o artística. La bandera portuguesa incluye esta esfera como símbolo de la era de los descubrimientos.

Lo anterior atribuye a este objeto material de la escuela tradicional un amplio valor semántico que desborda la dimensión instrumental de lo esférico, un formato por lo demás que también inspiró a Froebel, según hemos visto en el anterior cuadro iconográfico. La semántica de una esfera es cerrada, por un lado, pero abierta también a posibilidades interpretativas y estéticas.

Hace poco más de un decenio, en el año 2007, la Sociedad Española del Patrimonio Histórico Educativo organizó en el Centro Internacional de la Cultura Escolar - CEINCE unas jornadas nacionales bajo el título "La Cultura Material de la Escuela", en las que participaron representantes de la mayor parte de las regiones del país que han puesto en marcha experiencias museográficas (ESCOLANO, 2007). En el tiempo transcurrido desde entonces, nuestro entorno se ha poblado de museos y centros de memoria, reales y virtuales, relacionados con la escuela y la educación. En otros medios nacionales ha sucedido algo parecido. También se han promovido museos, centros de interpretación de la memoria escolar, redes documentales, publicaciones periódicas, series editoriales, eventos académicos y otros dispositivos de transmisión e intercambio de las experiencias que se han llevado a cabo en los anteriores centros de estudio y de difusión cultural. Estas iniciativas han generado conocimientos que sin duda han servido para implementar y reforzar el interés por 
las materialidades e incluso para incorporar sus contenidos a los programas de formación de los profesionales de la enseñanza.

Probablemente estamos acercándonos - piensan algunos observadores - a cubrir las expectativas de la fase acumulativa de los recursos físicos que configuran el archivo de la historia material de la formación, o hemos logrado reunir al menos un elenco suficientemente representativo del conjunto deseable para poder apoyar con eficiencia la construcción de esta modalidad de cultura. El crecimiento de los contenidos que pueblan las colecciones y los museos, o los reservorios virtuales, no se ha visto acompañado, sin embargo, como se ha señalado anteriormente, del aconsejable nivel de reflexividad sobre la significación y el sentido que tienen los legados reunidos hasta ahora. Tampoco se ha procedido a la evaluación crítica de los efectos sociales y culturales de estos medios materiales en las comunidades que los acumulan, organizan y difunden.

\section{MATERIALES Y EMPEIRIA}

En los epígrafes que siguen en este acercamiento al tema se exploran las vías intelectuales que se han ensayado en el pasado próximo a nosotros para poner en valor los testimonios materiales de la escuela como fuentes de la historia de la experiencia en educación. Bajo esta intención, queremos mostrar que la cultura material asociada a la historia de los procesos de la formación humana no es solo el resultado de una curiosidad museográfica sino una mediación intelectual que se construye y se comunica por necesidad hermenéutica. No es pues esta cultura un complemento ilustrativo de otros tipos de reconstrucción del pasado, sino la prueba testimonial que da acceso a la comprensión efectiva de la historia escolar desde las orientaciones de una historia material e intelectual de la experiencia bajo una perspectiva fenomenológica y crítica.

La historia material es un vector esencial de toda historia de la experiencia, en educación y en otros muchos sectores de la vida cotidiana. También lo es de las ciencias humanas que se ocupan de explicar e interpretar algún ámbito del mundo experiencial. No existe una historia de la experiencia que no se sustente en los hechos materiales vinculados a ella. El retorno a la empeiria supone en cierto modo una especie de giro intelectual, de signo probablemente aristotélico, que trata de corregir las desviaciones racionalistas e ideológicas que habían dominado hasta ahora en los saberes y enfoques acerca de la educación, incluidos los referentes a su historia. Busca asimismo tratar de entender las relaciones que los sujetos entablan con las cosas materiales y simbólicas en los contextos en los que se llevan a cabo las acciones prácticas de la formación. 
En otro lugar hemos glosado con alguna extensión el relato de ficción titulado El testamento de Aristóteles, obra en la que su autor, Alfredo Marcos, pone en boca del sabio de Estagira la epístola que este dirige a su discípulo y albacea Antípatro, en la que relata elementos de la memoria de su propia experiencia formativa en la infancia y da cuenta del utillaje habitual de las escuelas de su tiempo. El mismo Aristóteles y los niños de la época se puede leer en esta carta - "cargaban su tierna anatomía - ayudados por sus esclavos (los pedagogos) - con tablillas, punzones, trozos de tinta, tinteros, cítaras, horrísonas flautas, reglas para alinear las letras, libros de Homero y otros poetas, rollos de papiro, cálamos, ábacos, esponjas y espátulas" (MARCOS, 2002). De este ajuar instrumental que relata y detalla el anterior inventario se servirían los niños y los maestros de la Grecia clásica. Algunos de estos elementos, readaptados a los modos de civilización de cada época, se han seguido utilizando en fechas muy posteriores. El escrito alude asimismo a algunas de las prácticas que se llevaban a cabo con estos objetos, con lo que la historia material de la escuela se vincula en el relato a la historia de los métodos, e incluso se abre a la consideración de las habilidades que el manejo de los objetos requería, como en el caso de la escritura, y a la educación de las emociones y los sentimientos que, en algunos sectores, como el relativo a la música, estimulaba. He aquí pues un ejemplo del significado y valor que puede adquirir la historia de la cultura material para comprender los procesos y procedimientos formativos que promovía la pragmática escolar o empeiria en el mundo antiguo, más allá del elemental interés etnográfico que pueden tener estas fuentes.

También nos sugiere el anterior elenco de instrumentos las continuidades y los cambios que se han operado en las sucesivas culturas materiales. Objetos parecidos a los que formaron parte del utillaje de la escuela en tiempos de Aristóteles, e incluso de épocas anteriores, se siguieron empleando en instituciones de tiempos más modernos. Durante siglos, la escuela se ha servido de tablillas, pizarras, ábacos y otros objetos para apoyar la enseñanza. La materia de que están hechos ha variado de acuerdo a la evolución de la civilización y de las tecnologías, pero el formato y la funcionalidad se han mantenido en lo básico. Una tableta digital de hoy mantiene ciertas semejanzas de medida y estructura formal externa con la vieja pizarra individual. Y los ábacos de nuestra época, aunque sean de mesa, sobre papel o incluso virtuales, todavía conservan la vetusta estructura de líneas y bolas que tuvieron los primeros tableros contadores. Parece cierto que algunos hallazgos técnicos arcaicos acertaron hace muchos siglos en la definición formal de una especie de algoritmo material, el que sirve de modelo formal al ábaco o a la tableta, y ello podría llegar a tener algún tipo de significado cultural que habría quedado adherido a la fisicalidad misma de estos conocidos objetos, lo cual es un punto de reflexión para una historia intelectual de la experiencia y de las materialidades de la escuela. 


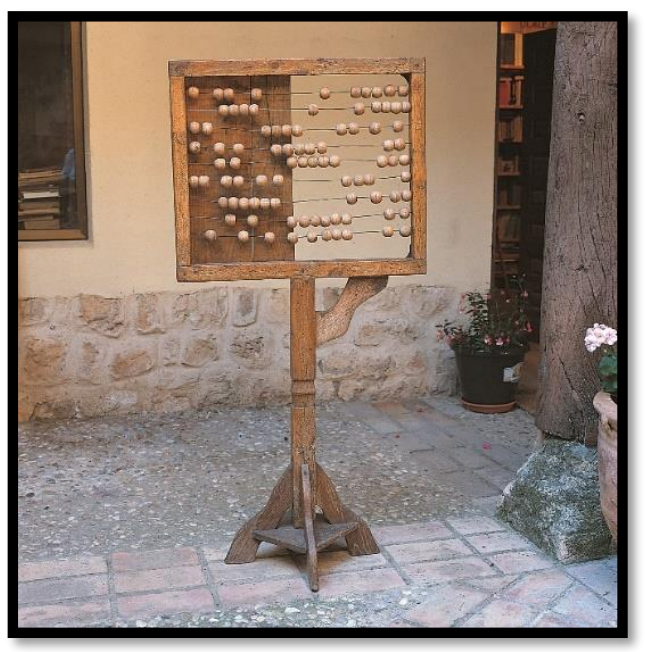

Figura 5 - Ábaco

Exposición estable del Centro Internacional de la Cultura Escolar - CEINCE - España Fonte: Agustín Escolano.

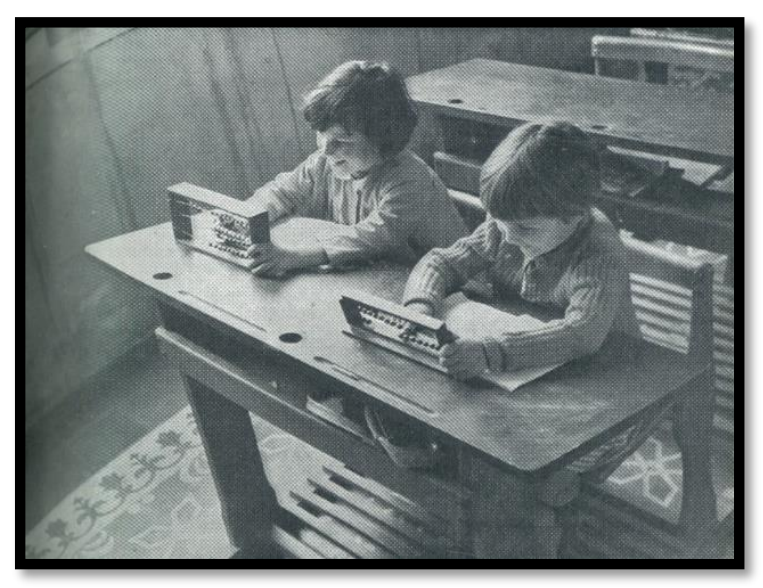

Figura 6 - Ábacos de mesa

Fondo de imágenes del Centro de Documentación y Orientación Didáctica de Enseñanza Primaria - CEDODEP - España 


\subsection{El ábaco como algoritmo}

El ábaco, instrumento de cálculo presente en todas las culturas, desde las antiguas civilizaciones orientales y las fluviales de Medio Oriente hasta la era digital, nació como objeto material asociado a los cálculos de los escribas. Ajustado a las prácticas contables que demandaba el mundo de la experiencia en una economía agraria se trasvasó a la escuela con el nombre de "tablero contador" y de "bolero".

El mundo antiguo se sirvió ya de este objeto en la enseñanza, y la baja Edad Media y el Renacimiento conocieron el nacimiento de las llamadas "escuelas de ábaco" a las que alude Carlo M. Cipolla (1983), demandadas por la incipiente burguesía menestral y mercantil de las ciudades, que coexistieron con las escuelas de solo leer y de leer y escribir.

A diferencia de los objetos glosados en el epígrafe anterior, que se originan en los supuestos teóricos que los fundamentan (idealismo froebeliano y cosmología antigua), este instrumento nace como invención empírica de las primitivas administraciones, y desde el mundo de la praxis contable se transfiere a la enseñanza que impartían los escribas y los maestros de contar y calcular.

Aunque sus formatos pueden ser de pie, de mesa, de colgar y de manual, la estructura visual del objeto mantiene en el tiempo una cierta forma y estructura que se puede considerar invariante, algorítmica. Las imágenes corresponden a la exposición "Mi Querida Escuela" y a otra fuente no identificada. 


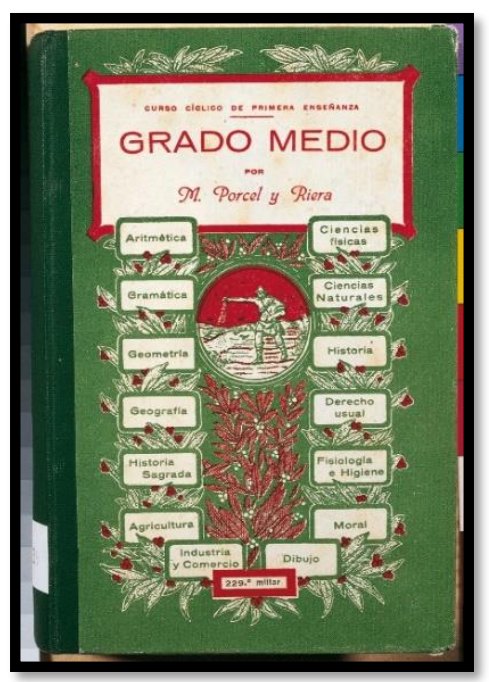

Figura 7 - Porcel disciplinas. Cubierta de Enciclopedia.

Fondo Centro Internacional de la Cultura Escolar - CEINCE - España Fonte: Agustín Escolano

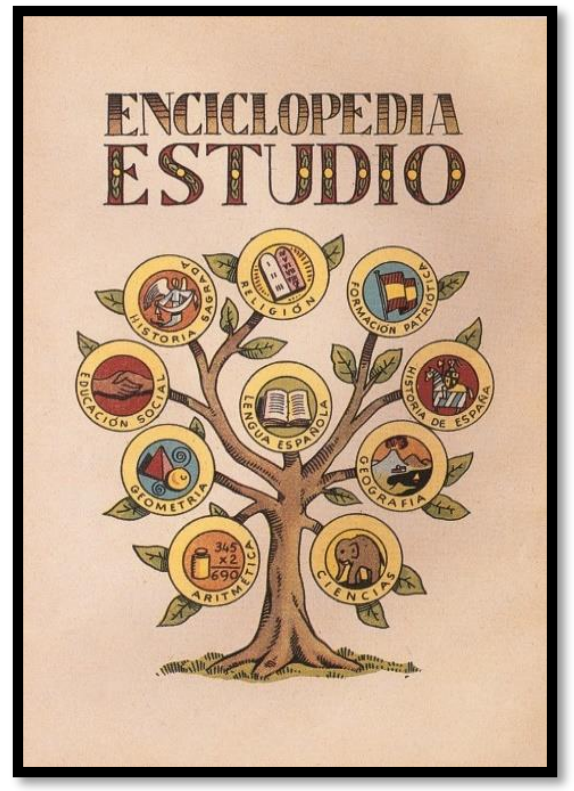

Figura 8 - Árbol Ciências. Imagen de cubierta interior de la Enciclopedia Estudio.

Gerona, Dalmáu. 1954.

Centro Internacional de la Cultura Escolar - CEINCE - España

Fonte: Agustín Escolano 


\subsection{El jardín de los saberes}

El árbol de las ciencias y el jardín del conocimiento han sido dos metáforas materiales de frecuente uso en la representación de las disciplinas que forman parte del currículum escolar. El árbol o la corona de flores (guirnaldas y florilegios son términos que dan nombre a algunos manuales de enseñanza) ejemplifican el tronco, las ramas, las hojas, las flores y los frutos, una visión organicista y natural del orden de los saberes de la escuela.

Complementariamente, la imagen del educador como jardinero que siembra y cultiva cuidadosamente las plantas del territorio que tiene a su cargo refuerza la interpretación de que la estructura y la variedad de los frutos de la tierra derivan del trabajo y la experiencia del agricultor, así como que su estudio, necesario para sobrevivir, es también el resultado de las prácticas de cultivo, es decir, de la experiencia.

La cubierta del libro del autor y editor balear Miguel Porcel y Riera muestra la corona de plantas que acoge el nombre de las materias de las que se compone el programa y la enciclopedia que las implementa. Las disciplinas escolares son los frutos materiales de la experiencia, no rúbricas formales.

El árbol de las ciencias que se incluye aquí, pertenece a la enciclopedia Estudio de la editora Dalmáu Carles, de Gerona, publicada a mediados de los años cincuenta del siglo pasado. Del tronco filológico (lengua) parten las distintas ramas o disciplinas que conformaban el programa o curriculum escolar. Así, el árbol es una gran metáfora naturalista de la estructura de los saberes.

Veamos otro tema relativo a las conexiones que operan entre la cultura material y la historia intelectual, también extraído de la cultura del mundo clásico. El ejemplo reenvía igualmente a la historia de los modos y métodos de enseñanza y de aprendizaje. Nos referimos a la cuestión que Martyn Lyons relata en su reciente historia de la lectura y escritura, tan asociada a la inserción de estas disciplinas instrumentales y culturales en la práctica o empeiria escolar. Es relevante el capítulo de esta obra en el que el autor examina los cambios culturales - también pedagógicos - que derivaron de una simple innovación material y técnica: la sustitución del papiro por el pergamino como soporte a utilizar en las prácticas de escribir/leer, mudanza que empezó a operarse en el siglo I de nuestra era (LYONS, 2012). 
Son bien conocidas las motivaciones que están en el origen de esta innovación material en la escritura y la lectura: la mayor resistencia de la piel de animal sobre la hoja de papiro, de origen vegetal, y la adquisición del producto en el mercado próximo, así como la posibilidad de usarse el nuevo soporte en sucesivas ocasiones, hecho que daría origen al palimpsesto. Como es sabido, esta innovación supuso el cambio del modelo rollo al modelo codex y ello afectó las prácticas de escritura, y consiguientemente de lectura, incluidas las relacionadas con su enseñanza y aprendizaje, como mostraron ya hace tiempo diversos trabajos del historiador Roger Chartier (CHARTIER, 1992). En el rollo, el texto se disponía bajo la forma de scriptio continua, sin saltos de página, ni capítulos, ni índices. No era fácil así seguir un texto ni orientarse en él. El papiro, que podía alcanzar varios metros de largo, era además muy difícil de manejar. El códice en cambio adoptó la forma de libro, un modelo que ha llegado, en soporte papel, hasta nuestros días. La estructura paginada del volumen facilitaba además otras prácticas lecto-escribanas. No necesitaba sostenerse con las dos manos, lo que liberaba una de ellas para poder leer, anotar, glosar, subrayar y realizar otras acciones.

El cambio material en la construcción del libro, extendido en cuanto a utilización a partir de los primeros siglos de nuestra era, había propiciado importantes innovaciones en la escritura, así como en los métodos de aprender y enseñar a leer y a escribir, e incluso en la misma organización de las escuelas y de las bibliotecas. Una nueva cultura de las prácticas de enseñanza estaba pues incoada en el cambio tecnológico que supuso el paso del rollo al codex. Más aún, tal giro tecnomaterial no solo afectó a los modos o procedimientos de enseñanza y aprendizaje, sino también a las nuevas formas de sociabilidad que se entablaron entre los sujetos que escribían y leían, a las estructuras usadas para organizar los acervos acumulados en la memoria escrita (libros, páginas, índices, notas, citas) y hasta a las prácticas de guardar y difundir el patrimonio cultural que se archiva en los nuevos dispositivos digitales (catálogos, repositorios).

Un nuevo cambio se opera ahora, en relación con estas prácticas de lectoescritura, con la aparición y uso de los procesadores de textos que ofrece el giro digital. El texto en pantalla recupera el modelo de rollo que hemos de leer $-y$ también de escribir - de arriba abajo, y no de modo horizontal, como se hacía al principio en la escritura en papiro. La versatilidad de las nuevas tecnologías de información/comunicación permite asimismo recoger algunas de las aportaciones del codex, como las relativas a la paginación e indexación, al tiempo que facilita incorporar otras nuevas como las relacionadas con el almacenamiento, la recuperación de textos y la conectividad. Una nueva pragmática de la escuela deriva por tanto de los cambios materiales que suscita el giro tecnológico. Los historiadores del futuro podrán examinar estos cambios y sus consecuencias en los procesos pedagógicos de formación. Y nosotros, los historiadores del tiempo presente, podemos jugar con los futuros incoados en la tecnología actual, así como hacer observar los impactos que las nuevas materialidades proyectan sobre el mundo de la educación, junto a las persistencias del

$\begin{array}{llllll}\text { (c) ETD-Educação Temática Digital } & \text { Campinas, SP } & \text { v.22 } & \text { n.4 } & \text { p. 793-811 } & \text { out./dez.2020 }\end{array}$


pasado. Tales juegos interpretativos suscitan en la actualidad un análisis intelectual con sentido hermenéutico que ha de pivotar sobre la dialéctica existente entre la innovación y la tradición, entre el patrimonio y lo emergente. Todo ello se ha de hacer necesariamente tomando como fuentes de referencia y conocimiento los elementos materiales de las dos culturas tecnológicas que en la actualidad conviven en la escuela en régimen de cohabitación e interacción.

\section{LOS OBJETOS INTELIGENTES Y EL “TERCER MAESTRO”}

Entre los objetos materiales "inteligentes" de la institución escolar debe considerarse, sin duda, la fábrica constructiva del edificio destinado a la educación institucionalizada, no solo por su diseño arquitectónico sino porque su materialidad ha sido soporte de imágenes, escrituras y símbolos que han operado e influido en las prácticas formativas y en la vida de toda la comunidad. También porque la estructura del inmueble ha sido un dispositivo de encauzamiento de los rituales que han gobernado la sociabilidad de los agentes que enseñan y aprenden. En sus microespacios los sujetos han desarrollado el esquema corporal, el sentido y los límites de la cohabitación social, el sentimiento estético y el orden disciplinario. $Y$, además, como constructo duradero, el espacio educativo ha operado como "tercer maestro" en varias generaciones que lo han habitado. Esta atribución magistral le fue conferida por María Montessori, quien consideraba que, junto a la maestra con los pares de edad, los educadores primarios, y la metodología que ella promovía, el albergue de la escuela era otro determinante de la educación de los menores (MONTESSORI, 2003). En la "escuela sin maestro", obra pictórica del italiano Francesco Bergamini, que ofrecemos en imagen, los niños se disponen en una coreografía circular en torno al fuego central del aula, recordando prácticas de sociabilidad más arcaicas que la escuela y la familia, asociadas a la vida de la tribu, como las que se configuraron en torno al fuego central en las comunidades primitivas y en las civilizaciones antiguas. 


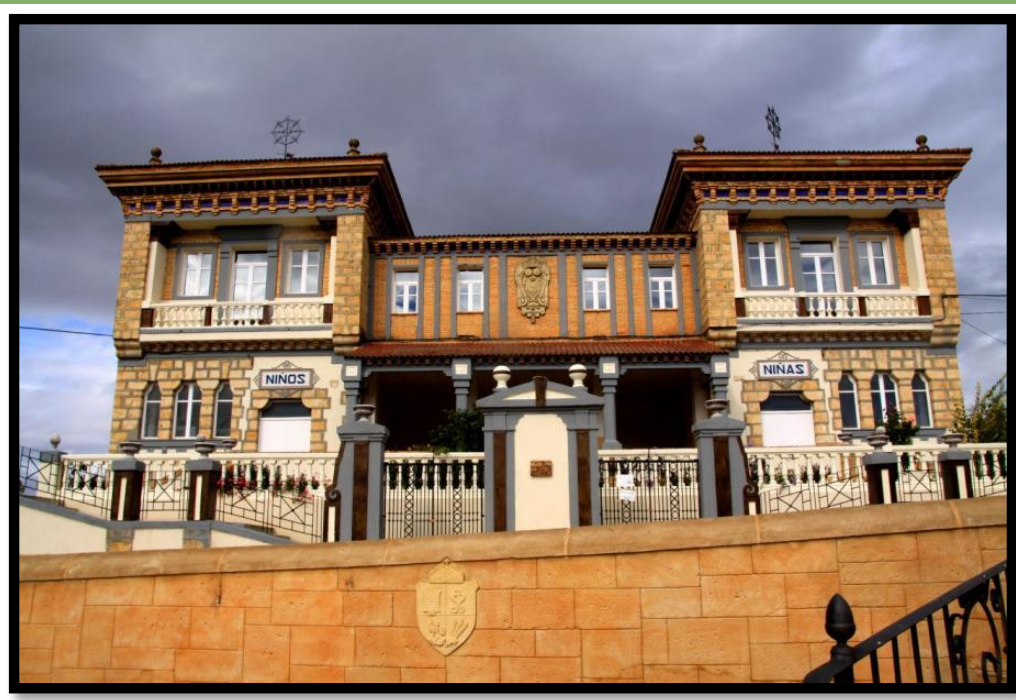

Figura 9 - Escuela de Quintanas de Gormaz, Soria, España, 1929. Fonte: Agustín Escolano.

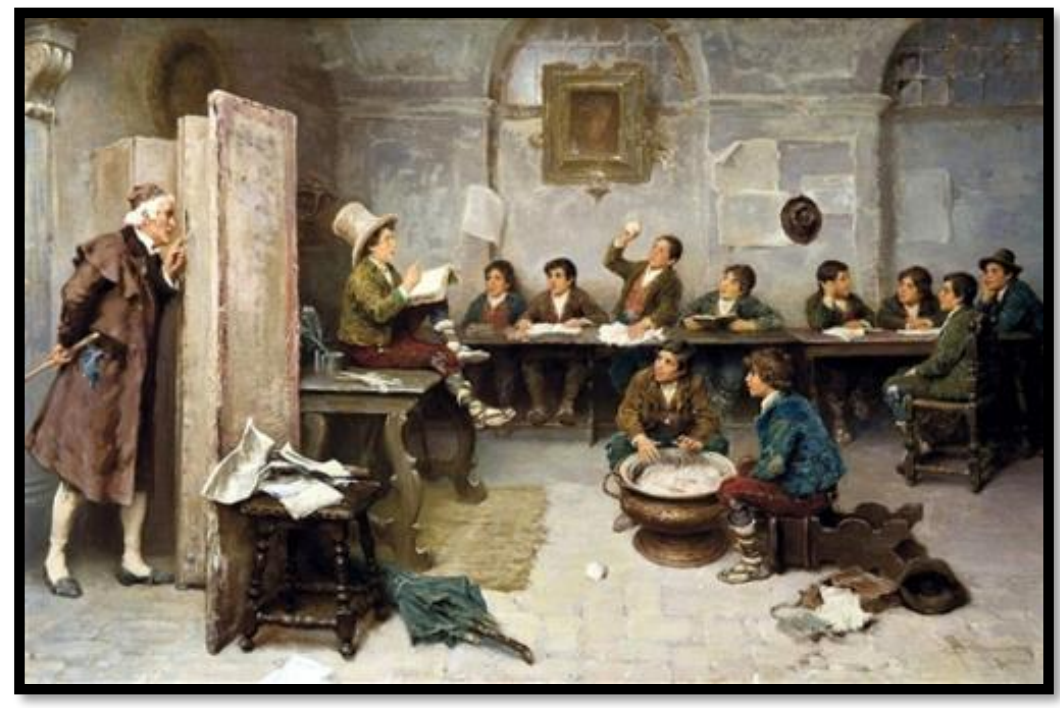

Figura 8 - El maestro ausente. Francesco Bergamini, c. 1850. Fonte: Matemolivaris blogia ${ }^{2}$

\footnotetext{
${ }^{2}$ http://matemolivares.blogia.com/2016/112203-la-escuela-vista-por-francesco-bergamini-1815-1883-.php
} 


\subsection{El tercer maestro}

Junto al educador y al método de enseñanza, el contenedor que alberga la educación es, como señaló María Montessori, el "tercer maestro", un habitat con inteligencia que condiciona el desarrollo del cuerpo, la pragmática de la formación y hasta los rituales que se escenifican dentro de su arquitectura. Maestro pues y educador total. De ahí la importancia que en los últimos años se ha venido atribuyendo a la arquitectura escolar.

Difícilmente se desalojará de la memoria el lugar donde los sujetos se han educado y se han socializado con los pares o iguales y con los adultos, representados por el formador, que además de enseñante encarna los roles propios de la autoridad. Como "templo del saber", según lo definió el arquitecto Leopoldo Torres Balbás, el edificio de la escuela ha ejercido además una fuerte influencia simbólica sobre las comunidades en las que se inscribió, y esto es también una valencia educativa.

La imagen del edificio que reproducimos aquí, elegida entre un sinnúmero de ellas, corresponde a la escuela rural de Quintanas de Gormaz, Soria, inaugurada en 1929. El edificio, de porte y estilo regionalista con ribetes historicistas, fue en su tiempo un verdadero "templo del saber", un "tercer maestro", de más relieve incluso que la Iglesia del lugar. Niños y niñas de sucesivas generaciones se formaron en esta escuela de conformidad con las costumbres que regulaban las relaciones de género en las sucesivas épocas en que estuvo abierto.

En la actualidad, después de casi un siglo y ya sin alumnos desde hace bastantes años, el edificio escolar ha sido restaurado e iluminado como un monumento artístico, convirtiéndose en patrimonio histórico educativo de la comunidad local, y sirviendo de museo de las artesanías tradicionales del entorno y de modelo de arquitectura regeneracionista, así como en centro de memoria para quienes se educaron entre sus muros.

La otra imagen presenta el interior de una escuela italiana del siglo XIX, en un cuadro del pintor costumbrista Francesco Bergamini. El maestro se oculta tras el biombo mientras los discípulos, en disposición circular en torno al fuego central, aprenden sin su presencia, estimulados por los "otros maestros", los pares de edad y el habitáculo que opera como "tercer maestro". El artista titula su obra "el maestro ausente" y ratifica que los otros maestros, el ámbito espacial y los compañeros, también son agentes formativos.

He aquí algunos ejemplos inteligibles que ponen de manifiesto la interconexión de la historia material con la historia intelectual y a la vez con la historia de la experiencia. Estos ejemplos evidencian cómo a partir de los testimonios escolares primarios que se asumen como fuentes -las materialidades observables y manejables - se puede acceder a reconstruir una historia cultural de la educación mucho más compleja y también más pragmática, como la que corresponde a los métodos de aprender, a los modos de enseñar, a la comprensión de los sujetos implícitos (implied reader) en los sistemas de objetos y en los textos, y de las formas de sociabilidad que se dan o se suscitan entre ellos. En cuanto que se constituyen en testigos del pasado nos remiten a otros aspectos de los procesos formativos que están incluidos en la relación de los hombres con las cosas, una relación que siempre es cultural, y 
cuya interpretación, desde el análisis centrado en las prácticas, es siempre de naturaleza intelectual. Por esta vía podemos caminar de la empeiria a la hermenéutica de la cultura.

Uno de los primeros ensayos que se publicaron acerca de las materialidades de la escuela, la obra editada por los británicos Martin Lawn y lan Grosvenor, tenía como leitmotiv central la búsqueda de conexiones entre los objetos con los sujetos y las rutinas, esto es, las prácticas que se ponían en acción con los materiales. Los autores tratan de superar la posible dicotomía que a veces se sugiere entre los objetos y los sujetos. Los objetos que nos parecen inanimados fueron creados para ser utilizados por los actores de la educación, los alumnos y los enseñantes. Estos materiales cobran justamente significación cuando se ponen en relación con los comportamientos de los usuarios que se sirvieron de ellos (LAWN; GROSVENOR, 2005).

En el pasado no alejado de nosotros, muchos de estos materiales se abandonaron a los rincones del olvido y a los espacios de la obsolescencia, y en el mejor de los casos a los museos de curiosidades etnográficas. Ha sido en las dos últimas décadas cuando los objetos han entrado a formar parte del archivo de fuentes de interés historiográfico, a la par de los analistas del pasado que han puesto de relieve que estas cosas contienen una semántica cultural cuyo desvelamiento es imprescindible para conocer las prácticas de la cultura empírica que en ellas reside. Este es justamente el punto de enlace entre la historia material, la de la experiencia y la intelectual, toda vez que no hay duda de que la operación interpretativa que se lleva a cabo al estudiar las fuentes objetuales con el auxilio de la semiología y la hermenéutica es una tarea estrictamente intelectual.

Más aún, la anterior historia intelectual de la experiencia puede entrar en diálogo con otras disciplinas, como se sugiere en varios puntos de este trabajo, y de un modo especial lo ha de hacer con la antropología cultural, con la historia de la técnica y con la etnología, además de con otras ciencias sociales. Un artefacto escolar es un ingenio técnico que nace en el contexto de una cultura para dar respuesta a ciertas necesidades del grupo que lo utilizará. En algunos casos, su diseño está influido por las formas de otros dispositivos empleados en la vida cotidiana de las comunidades donde se gesta y aplica. En cualquier caso, un material formateado es una pieza que se puede incorporar a la historia de la tecnología.

Los autores recuerdan a los efectos anteriores los escritos de Walter Benjamin en los que el conocido filósofo de la escuela crítica de Fráncfort destacó el hecho, generalizable a todas las culturas, de que el modo en que los hombres construyen y usan las cosas materiales en los entornos en que habitan es una importante cuestión de naturaleza intelectual, y no solo una forma de creación con fines instrumentales y funcionales. Este es en esencia el núcleo discursivo central que plantea nuestro estudio: la estrecha y necesaria interacción entre la cultura material con la historia intelectual.

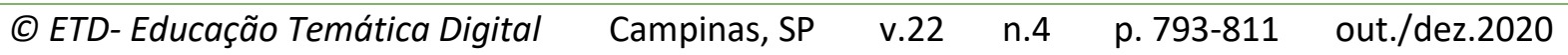




\section{REFERÊNCIAS}

CHARTIER, Roger. El orden de los libros. Barcelona: Gedisa, 1992.

CIPOLLA, Carlos M. Educación y desarrollo en Occidente. Esplugas de Llobregat: Ariel, 1983.

ESCOLANO, Agustín. La cultura material de la escuela In: ESCOLANO, Agustín. La cultura material de la escuela. En el centenario de la Junta para la Ampliación de Estudios, 19072007. Berlanga de Duero, España: CEINCE, 2007. p. 15-27.

ESCOLANO, Agustín. La cultura empírica della scuola. Ferrara: Volta la Carta, 2016.

LAHOZ, Purificación. El modelo frioebeliano de espacio-escuela. Su introducción en España. Historia de la Educación, v. 10, p.107-134, 1991. Disponible en:

https://revistas.usal.es/index.php/0212-0267/article/view/6915/6896. Acceso en: 9 sept. 2020.

LAWN, Martin; GROSVENOR, Ian. Materialities of Schooling, Oxford: Symposium Books, 2005.

LYONS, Martyn. Historia de la lectura y de la escritura en el mundo occidental. Buenos Aires: Editoras del Calderón, 2012.

MONTESSORI, María. El método de la pedagogía científica. Madrid: Biblioteca Nueva, 2003.

MARCOS, Alfredo. El testamento de Aristóteles. León: Edilesa, 2002.

PRÜFFER, Johan. Fiedrich Froebel. Barcelona: Labor, 1932.

Revisão gramatical realizada por: Sindy Melissa Metaute Arango.

E-mail: sindy.metaute@udea.edu.co. 